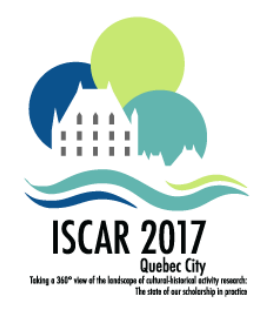

\title{
Cognitive Psychology of Activity: Attention as a Constructive Process
}

\author{
Maria Falikman \\ Lomonosov Moscow State University \\ National Research University Higher School of Economics \\ Russian Academy of National Economy and Public Affairs \\ Moscow, Russia
}

Alexander Asmolov

AGAS@MAIL.RU

Lomonosov Moscow State University

Moscow, Russia

\begin{abstract}
The problem of consciousness is one of the core problems in the contemporary cognitive science. Driven by the neuroimaging boom, most researchers look for the neural correlates or signatures of consciousness and awareness in the human brain. However, we believe that the explanatory potential of the cultural-historical activity approach to this problem is far from being exhausted. We propose Cognitive Psychology of Activity research program, or the activity theory-based constructivism as an attempt to account for multiple phenomena of human awareness and attention. This approach relies upon cultural-historical psychology and the concept of mediation by Lev S. Vygotsky, activity theory and the concept of image generation by Alexey N. Leontiev, the physiology of activity and the metaphor of movement construction by Nikolai A. Bernstein, transferred to the psychology of perception as image construction by a number of Russian researchers in 1960-es, and the understanding of attention as action by evolutionary cognitive psychologists of 1980-es. The central concept of our approach is a concept of task, defined by Leontiev as "a goal assigned in specific circumstances". The goal determines choice and use of available cultural means ("mediators") consistent with the circumstances or conditions of task performance, which in turn provide for the construction of processing units allowing for more successful ("attentive") performance and for the awareness of visual stimuli which could otherwise be missed or ignored. The perceptual task accomplishment is controlled at several levels organized heterarchically, with possible strategic reorganizations of this system demonstrating the constructive nature of human cognition.
\end{abstract}


The problem of consciousness is one of the core problems in the contemporary cognitive science. Driven by the new horizons of neuroimaging, most researchers look for the neural correlates or signatures of consciousness and awareness in the human brain at various levels of biological organization. However, despite the tempting progress in this area, we believe that the explanatory potential of the cultural-historical activity approach to the problems of consciousness and cognition is far from being exhausted. At the same time, recent years of cognitive science development demonstrate the convergence of its research program with the basic principles of cultural-historical psychology and the activity theory, with the growing interest towards embodiment of cognition, its evolutionary aspects, its emotional regulation, and social and cultural determination (for the discussion of this convergence, see Falikman (2014b)). For instance, the cultural-historical activity theory is considered as a possible foundation for a metatheory of human cultural development (Cole \& Packer, 2015).

Recently the historical evolutionary approach to the body-mind problem and to the understanding of consciousness has been proposed in Russian psychology (Asmolov, Shekhter, \& Chernorizov, 2016). Departing from the critical analysis of the "mythology of neural correlates of consciousness" biased towards the "simple living" (reductionist) type of explanation, this approach treats consciousness as a product of evolution of complex purposeful living systems, not reducible to neural processes in the brain and possessing its own evolutionary significance in pre-adaptive tasks. Consciousness provides for the very possibility of "expectation of the unforeseen" (something which has never happened before and might never happen in the future), which in principle cannot be reduced to the previous adaptive experience and therefore, obviously has a constructive nature.

In the current paper, we propose the activity theory-based constructivism as an attempt to account for multiple phenomena of human awareness and attention. Constructivism in psychology is currently considered not as a unitary approach, but as a bunch of approaches grouping into at least three branches (Raskin, 2002): radical constructivism (e.g. Maturana and Varela (1987)), social constructionism (e.g. Gergen (1999)), and the theory of personal constructs (Kelly, 1955). Among cognitive psychologists, the constructive nature of cognition has been discussed since F.C. Bartlett's seminal works on the subject's activity and the role of schemata in remembering (Bartlett \& Burt, 1933) through U. Neisser's ideas of perceptual cycle with the schema as its key internal part and anticipation as its function in the perceptual activity regulation (Neisser, 1976), up to the so-called cognitive embodiment (Varela, Thompson, \& Rosch, 1991) and inactivism (e.g. O'Regan and Noë (2001)) with their basic idea of knowledge as a result of a subject's immediate sensorimotor involvement and constructive interaction with the world. Though the basic trend in the mainstream cognitive psychology was moderate rather than radical constructivism (Anderson, Reder, \& Simon, 1998), since the beginning of the $21^{\text {th }}$ century the ideas of embodiment as a part of radical constructivism and the evolutionary approach towards cognition have become widespread in cognitive science (Wilson, 2002), together with the "extended mind" idea closely related to Vygotsky's ideas of mediation and cultural-historical development (e.g. Malafouris (2013)). In Russian psychology, there are at least two modern constructivist approaches intrinsically inheriting cultural-historical psychology and the theory of activity 
frameworks: the above-mentioned historical evolutionary approach (Asmolov, 1998) and the experimental psychosemantics of consciousness (Petrenko \& Suprun, 2015).

The approach we propose in this paper also relies upon (I) cultural-historical psychology and the concept of mediation by Lev S. Vygotsky (Vygotsky, 1978), which has found its further development in the theory of systemic organization and dynamic localization of higher mental functions by Alexander R. Luria (e.g. Luria (1973)); (II) the activity theory and the concept of image generation by Alexey N. Leontiev (Leont'ev, 1978); (III) the physiology of activity and the metaphor of movement construction by Nikolai A. Bernstein (Bernstein, 1967), transferred to the psychology of perception through the "image construction" metaphor by a number of Russian researchers starting from the 1960-es (e.g. Zinchenko (1966); Zinchenko and Vergiles (1972)) up to the 2000-es (Velichkovsky (2002)), and (IV) the understanding of attention as action by evolutionary-oriented cognitive psychologists of the 1980-es (e.g. Allport (1987); Neumann, Heijden, and Allport (1986)). We assume that integration of concepts which have emerged within cognitive psychology with (I) the idea of the levels of task performance organization declared in the activity theory and the physiology of activity and (II) the idea of its mediated nature set forward in cultural-historical psychology opens the opportunities of new interpretation of human consciousness and attention and their constructive nature.

The cornerstone of our approach is a concept of task, defined by Leontiev as "a goal assigned in specific circumstances" (Leont'ev, 1978). This concept, which dates back to the classical psychology of consciousness, and to the Wuerzburg school of the psychology of thought in particular (Elliot \& Fryer, 2008), became a core concept for Bernstein's physiology of activity and was successfully applied in the studies of visual perception and eye movements within the activity theory framework (e.g. Gippenreiter and Romanov (1972)). The task drives the construction of a multi-level functional system providing for the efficient performance, and determines what will be consciously perceived by the subject. The conscious goal guides choice and use of available cultural means (or "mediators") consistent with the circumstances or conditions of task performance, which in turn provide for the construction of processing units allowing for more successful ("attentive") performance and for the awareness of visual stimuli which could otherwise be missed or ignored. Among the most remarkable examples of such mediation are the variety of so-called "word superiority effects" in visual attention tasks Falikman $(2008,2011)$, which we will discuss below.

To further elaborate on the Bernsteinian framework, the perceptual task accomplishment is controlled at several levels organized hierarchically (cf. Velichkovsky (2002)). Only the top ("leading") level corresponds to the goal and is consciously represented to the observer. We propose that this leading level also determines the size of "perceptual units" available to the awareness. The "unitization" controlled by the leading level through top-down influences in the visual system could be based either on the observer's former experience or on the active strategy selected or built up by the observer to perform the task. This construction of new perceptual units provides for higher performance if it doesn't contradict to the task requirements. 
Effects of perceptual units construction on the observer's perceptual activity (e.g. Falikman (2011)) demonstrate that attentional limitations experimentally demonstrated in cognitive psychology since 1950-es are not necessarily limitations of the "information processing system" in general (or its central "limited capacity channel"), but might rather refer to a specific level of perceptual activity organization, which takes on a role of a leading level in the observer's perceptual activity, but could in principle be overbuilt with another level as a result of the strategy applied by an observer to perform the task efficiently.

It has probably become clear that the concept of perceptual task is intimately related to the problem of attention, one of the central issues in psychology of cognition since the rise of classical psychology of consciousness (Wundt, 1896). The concept of attention is probably among the most ambiguous and elusive concepts in psychology, and the very existence of attention as a specific process with its own functions and mechanisms has been challenged a lot of times since the very first steps of psychology as a science (James, 1890) and up to the contemporary cognitive psychology (e.g. Pashler and Sutherland (1998)).

William James, who authored the famous formula "Everyone knows what attention is", proposed to distinguish two groups of the theories of attention: "cause theories" and "effect theories" (James, 1890), a distinction still relevant for cognitive psychology (Fernandez-Duque \& Johnson, 2002). "Cause theories" consider attention as a separate process influencing information processing, explaining the effects observed in perceptual task accomplishment, and determining the subjective conscious representation available for the observer's report. On the opposite, "effect theories" treat attention as a by-product of information processing, which can be exhaustively explained from the architecture and functioning of the information processing system, or from the organization of the perceptual task accomplishment. Although the dispute between two types of theories is still far from being resolved. Our approach might be helpful in facing this problem.

In our experimental studies, we used a phenomenon described in the end of the $19^{\text {th }}$ century in Wilhelm Wundt's experimental psychology laboratory by Cattell (1886). This phenomenon, known as the "word superiority effect", has later become a popular target for cognitive psychologists (McClelland \& Rumelhart, 1981; Reicher, 1969; Wheeler, 1970). The word superiority effect refers to the better recognition of letters presented within words as compared to isolated letters and to letters presented within random nonword letter strings, when presentation is brief, or masked, or contains visual noise, etc. In the context of recent theoretical discussions, the word superiority effect can be considered as an example of top-down influences upon visual information processing. For us, it is a suitable phenomenon to demonstrate, how mediation and hierarchical structure of activity can be applied as explanatory principles for understanding human perceptual activity. The use of the native language words and letters as stimuli opens vast opportunities of hierarchical organization of visual information for an observer and wide opportunities for a researcher to study a variety of perceptual tasks using the same stimulation. Both letters and words are acquired quite early in the course individual development as a part of culture. Their process is highly automatized across a wide variety of conditions. At the same time, this type of stimulus material allows demonstrating perceptual system 
reconstruction and reconfiguration depending on the task, especially if the task (as a goal under given conditions) violates habitual perceptual conditions and requirements, and, therefore, prompts reorganization of perceptual operations available in the observer's individual experience.

Our experiments on the word superiority effects using a variety of attentional paradigms, such as dual-task rapid serial visual presentation, spatial cueing, visual search Falikman (2011, 2014a, 2014b) show that embedding a letter into a larger perceptual unit or "chunk" leads, not only to a more efficient identification of this letter, a result repeatedly replicated in cognitive psychology, but also to a more efficient accomplishment of an attentional task regarding this letter. It is constructive perceptual activity, mediated by the word form, which provides for overcoming "central limitations" described in cognitive psychology and for constructing a conscious representation of a visual object which could otherwise have been lost by an observer. These results echo a constructivist concept of "operational units of perception" introduced within the framework of A. N. Leontiev's activity theory (for a discussion in English, see Zaporozhets (2002)).

We distinguish two types of mediation behind the word superiority effects in human visual perception and attention. They correspond to two types of perceptual units which might be constructed by an observer during the perceptual task accomplishment. We call them "structural perceptual units" and "functional perceptual units". Structural units rely on the observer's prior experience and on memory representations activated during the performance of the task and can thus take place without conscious regulation, even under inattention (Gorbunova \& Falikman, 2010, 2011). Functional units are determined by subjective strategies of the perceptual task accomplishment and seem to be a certain mode of processing providing for the more efficient report on separate letters within words (Falikman, 2002). What's interesting, the same strategies of functional unit's construction can in principle be applied to random letters, leading to the same enhancement of processing. For example, in one of our studies (Falikman \& Stepanov, 2012) we used a dual-task rapid serial visual presentation $(R S V P)$ paradigm with letter-by-letter presentation of mid-frequency Russian nouns, at a rate about 9 letters per second. We have demonstrated that the robust lack of visual awareness known as "the attentional blink" (Raymond, Shapiro, \& Arnell, 1992), normally observed in this paradigm, disappears for target letter stimuli embedded in words. Using word and nonword strings with instructions "to read words" and "to identify letters" in addition to an "attentional blink" inducing letter identification task, we have also demonstrated that this word superiority effect is due to the controlled strategy rather than to the automatic word processing. Finally, by introducing an extra probe stimulus in letter strings containing words, we have also shown that the attentional blink does not completely disappear but rather shifts towards the end of a to-be-reported word as a new functional unit of visual information processing. We hypothesize that in the dual-task rapid serial visual presentation, the subject's perceptual activity is internally mediated by the "word form" representation, which becomes a means of this task accomplishment.

On the opposite, when a target letter is embedded in the simultaneously presented word, the mediation seems to be external, and the use of words as cultural means of the 
perceptual task accomplishment is more automatized. This hypothesis is supported by our experiments where we've demonstrated the word superiority effect under various conditions of inattention: e.g. within the "attentional blink" in a rapid serial visual presentation of simultaneously presented letter strings forming words and non-words (Gorbunova \& Falikman, 2010), and after an invalid spatial cue redirecting the observer's attention away from the target letter string to the opposite side of the visual field (Gorbunova \& Falikman, 2011). However, there is no word superiority effect if spatial attention is automatically redirected within words, as, for example, in the perceptual latency priming paradigm (Sinitsyna, 2009). The structural unit cannot be formed in this situation, as compared to spatial redirection of attention away from the word as a whole. We assume that this result reveals a difference between two types of operations distinguished by A.N. Leontiev in his analysis of the structure of activity (1978): "adaptive operations", which have never been consciously accessible and can be considered as adaptations to specific conditions or circumstances of the situation of task performance, and "conscious operations", or automatized actions which had previously been accessible for consciousness. Turning back to our studies of word superiority effects, whereas spatial shifts of attention seem to be basic "adaptive operations" deployed at one of background levels of perceptual activity regulation, construction of information processing units ("unitization") is a flexible "conscious operation" which can be deployed into a goal-driven act if necessary.

Last, but not least, when the word extraction (and thus "unitization") itself requires a separate goal-driven perceptual act, a situation typical of a so-called Muensterberg's selective attention test, in which words are embedded in a number of random letter strings (Burtt, 1917), an observer might avoid using a word as a means of perceptual task accomplishment, when a target is a separate letter within a word. In a number of studies of letter search in large letter arrays (e.g. Falikman (2014a)), we used a modified selective attention task. In the standard Muensterberg test, an observer has to find as many words in a letter array as possible within a limited time. In our studies, observers searched for prespecified letters in a large array of random letters which included words (24 Russian mid-frequency 6-letter nouns). Target letters were either always embedded or never embedded in the words. In the control condition, there were no words in the array. We discovered a dissociation of letter search efficiency (no statistically significant differences between the three conditions) and subjective representation of one's performance (drastic differences between the two experimental conditions, with words estimated as subjectively supporting search only in the first condition).

To understand this dissociation, we compared time-limited search for prespecified letters and search for words in the same letter arrays combining behavioral data and eyetracking (Yazykov \& Falikman, 2016). Search efficiency differed in the two conditions: letter search proved much easier and faster than word search (for the same time interval of one minute, mean search performance was $75 \%$ for letters and $46 \%$ for words). The pattern of eye fixations also differed: when searching for words, observers performed more fixations both between and within words, drastically changing the search pattern as compared to letter search in the same arrays containing words. Therefore, words would 
not mediate the observer's search for target letters, even though they might occasionally bias attention towards their locations.

Summing up the examples provided above, linguistic mediation of visual attention in perceptual tasks requiring letter recognition reveals itself through the phenomena which unambiguously show that embedding a target letter in a word allows reorganizing an observer's attention to enhance performance in the attentional task. Within cognitive psychology and cognitive neuroscience framework, we regard mediation as construction of a functional system providing for the efficient perceptual task accomplishment and setting a specific type of interaction between bottom-up and top-down processes in the hierarchically organized human vision. This functional system is aimed at constructing visual information processing units to accomplish the task more efficiently. The concept of "attention" with its effects on performance thus describes the operating mode of this externally or internally mediated functional system.

We believe that our studies establish a framework for the interdisciplinary research program which could be labeled Cognitive Psychology of Activity, and which integrates basic principles and concepts proposed by Vygotsky, Leontiev, Luria and Bernstein with current trends in cognitive science.

\section{References}

Allport, D. A. (1987). Selection for action: Some behavioral and neurophysiological considerations of attention and action. Perspectives on perception and action, 15, 395-419.

Anderson, J. R., Reder, L. M., \& Simon, H. A. (1998). Radical constructivism and cognitive psychology. In D. Revitch (Ed.), Brookings papers on education policy (pp. 227-278). Washington DC: JSTOR.

Asmolov, A. G. (1998). Historical evolutionary approach: Introductory notes. In A. G. Asmolov (Ed.), Vygotsky today: On the verge of non-classical psychology (pp. xix-xxix). New York: Nova Publishers.

Asmolov, A. G., Shekhter, E. D., \& Chernorizov, A. M. (2016). What is life from the psychological point of view: A historical evolutionary approach to the psychophysical problem. Voprosy psikhologii., 2, 3-23.

Bartlett, F. C., \& Burt, C. (1933). Remembering: A study in experimental and social psychology. British Journal of Educational Psychology, 3(2), 187-192.

Bernstein, N. A. (1967). The co-ordination and regulation of movements. New York: Pergamon Press Ltd.

Burtt, H. E. (1917). Professor munsterberg's vocational tests. Journal of Applied Psychology, 1(3), 201.

Cattell, J. M. (1886). The time it takes to see and name objects. Mind, 11(41), 63-65.

Cole, M., \& Packer, M. (2015). A bio-cultural-historical approach to the study of development. In M. J. Gelfand, C.-Y. Chiu, \& Y.-Y. Hong (Eds.), Handbook of advances in culture and psychology (Vol. 6). London: Oxford University Press.

Elliot, A. J., \& Fryer, J. W. (2008). The goal construct in psychology. In J. Shah \& W. Gardner 
(Eds.), Handbook of motivation science (Vol. 18, pp. 235-250). New York: Guilford Press. Falikman, M. V. (2002). Word preference effect and the attentional blink: Who will have the upper hand? In E. V. der Meer (Ed.), Proceedings of the forty-third kongress der deutschen gesellschaft fuer psychologie (p. 324). Lengerich: Pabst Science Publishers. S.

Falikman, M. V. (2008). On the linguistic mediation of visual attention. ISCAR, Ecologies of Diversities: The Developmental and Historical Interarticulation of Human Mediational Forms. Book of Abstracts., 62.

Falikman, M. V. (2011). Word superiority effects across the varieties of attention. Journal of Russian \& East European Psychology, 49(5), 45-61.

Falikman, M. V. (2014a). Attention and chunking in visual search among letter stimuli. Journal of the Higher School of Economics, 11(2), 150-159.

Falikman, M. V. (2014b). Cognition and its master: New challenges to cognitive science. In Cambridge handbook of cultural-historical psychology (pp. 474-487). Cambridge University Press.

Falikman, M. V., \& Stepanov, V. (2012). Chunking in rapid serial visual presentation: Consequences for visual awareness. Neuroscience and cognition: Consciousness and cognitive control, 33-34.

Fernandez-Duque, D., \& Johnson, M. L. (2002). Cause and effect theories of attention: The role of conceptual metaphors. Review of general psychology, 6(2), 153-165.

Gergen, K. J. (1999). An invitation to social construction. London: Sage.

Gippenreiter, Y. B., \& Romanov, V. Y. (1972). A method of investigation of the internal form of visual activity. In R. MacLeod \& H. L. Pick (Eds.), Perception: Essays in honor of James J. Gibson. New York: Cornell University Press.

Gorbunova, E., \& Falikman, M. (2010). Word superiority within the attentional blink. Journal of Vision, 10(7), 203.

Gorbunova, E., \& Falikman, M. (2011). Is word superiority effect the same for attended and inattended words? Perception ECVP abstract, 40(12).

James, W. (1890). The principles of psychology new york, vol 1. New York: Henry Holt.

Kelly, G. A. (1955). The psychology of personal constructs. Vol I, II. New York: Norton.

Leont'ev, A. N. (1978). Activity, consciousness, and personality. Englewood Cliffs, NJ: Prentice-Hall.

Luria, A. R. (1973). The working brain. New York: Basic Books.

Malafouris, L. (2013). How things shape the mind: A theory of material engagement. Cambridge, MA: MIT Press.

Maturana, H., \& Varela, F. (1987). The tree of knowledge. a new look at the biological basis of human understanding. Boston: Shambhala/New Science Library.

McClelland, J. L., \& Rumelhart, D. E. (1981). An interactive activation model of context effects in letter perception: Part I. an account of basic findings. Psychological review, $88(5), 107-375$.

Neisser, U. (1976). Cognition and reality: Principles and implications of cognitive psychology. San Francisco: W.H. Freeman.

Neumann, O., Heijden, A. H. C., \& Allport, D. A. (1986). Visual selective attention: Introductory remarks. Psychological Research, 48(4), 185-188.

O'Regan, J. K., \& Noë, A. (2001). A sensorimotor account of vision and visual consciousness. Behavioral and brain sciences, 24(5), 939-973. 
Pashler, H. E., \& Sutherland, S. (1998). The psychology of attention (Vol. 15). Cambridge, MA: MIT press.

Petrenko, V. F., \& Suprun, A. P. (2015). Methodology of psychosemantics in the context of the philosophy of postnonclassical rationality and quantum physics. Herald of the Russian Academy of Sciences, 85(5), 434-442.

Raskin, J. D. (2002). Constructivism in psychology: Personal construct psychology, radical constructivism, and social constructionism. In J. Raskin \& S. Bridges (Eds.), Studies in meaning: Exploring constructivist psychology (pp. 1-25). New York: Pace University Press.

Raymond, J. E., Shapiro, K. L., \& Arnell, K. M. (1992). Temporary suppression of visual processing in an rsvp task: An attentional blink? Journal of experimental psychology: Human perception and performance, 18(3), 849.

Reicher, G. M. (1969). Perceptual recognition as a function of meaningfulness of stimulus material. Journal of experimental psychology, 81(2), 275-280.

Sinitsyna, M. (2009). Top-down influences upon visual information processing under metacontrast masking. Master's Thesis. Supervised by Dr. M. Falikman. Moscow: Lomonosov Moscow State University.

Varela, F. J., Thompson, E., \& Rosch, E. (1991). The embodied mind: Cognitive science and human experience. Cambridge, MA: MIT press.

Velichkovsky, B. M. (2002). Heterarchy of cognition: The depths and the highs of a framework for memory research. Memory, 10(5-6), 405-419.

Vygotsky, L. S. (1978). Mind in society: The development of higher psychological processes. Cambridge: Harvard University press.

Wheeler, D. D. (1970). Processes in word recognition. Cognitive Psychology, 1(1), 59-85.

Wilson, M. (2002). Six views of embodied cognition. Psychonomic bulletin E review, 9(4), 625-636.

Wundt, W. (1896). An introduction to psychology. New York: Arno Press.

Yazykov, S., \& Falikman, M. (2016). Eye movements in spontaneous and controlled word detection in letter arrays. Psychology. Journal of Higher School of Economics, 13(2), 410420.

Zaporozhets, A. V. (2002). Perception, movement, and action. Journal of Russian $\mathcal{E}$ East European Psychology, 40(4), 53-93.

Zinchenko, V. P. (1966). Perception as action in perception and action. In Proceedings of the 18th international congress of psychology. Moscow.

Zinchenko, V. P., \& Vergiles, N. Y. (1972). Formation of visual images. New York: Springer. 